\title{
Keanekaragaman Jenis-Jenis Anggrek di Hutan Lamasi Desa Murnaten Kecamatan Taniwel Kabupaten Seram Bagian Barat Maluku
}

\author{
Diversity of orchid species in the Lamasi Forest, \\ Murnaten Village, District of Taniwel \\ West Seram Maluku
}

\author{
Dece Elisabeth Sahertian ${ }^{1)}$ dan Sherly Meiske Seay ${ }^{1)}$ \\ ${ }^{1)}$ Jurusan Biologi, Fakultas MIPA, Universitas Pattimura \\ Email:dece.elisa@gmail.com
}

Diterima 15 Januari 2015; Dipublikasi 1 Maret 2015

\begin{abstract}
Abstrak
Penelitian ini mempelajari keanekaragaman jenis-jenis anggrek di Hutan Lamasi, Desa Murnaten, Kecamatan Taniwel, Kabupaten Seram Bagian Barat Maluku. Tujuan penelitian ini adalah untuk mengetahui keanekaragaman spesies anggrek di Hutan Lamasi. Metode yang digunakan dalam penelitian adalah metode transek liniar kuadrat dengan plot $10 \mathrm{~m}$ x $10 \mathrm{~m}$. Hasil menunjukkan bahwa spesies anggrek diklasifikasikan dalam 1 kelas, 2 ordo, 1 famili, 10 genus dan 13 spesies. Nilai indeks keanekaragaman menunjukkan tingkat keanekaragaman yang rendah, demikian juga dengan nilai indeks dominan.
\end{abstract}

Kata kunci: jenis anggrek, keanekaragaman, Hutan Lamasi.

\begin{abstract}
The research study the diversity of orchid species in the Lamasi Forest, Murnaten Village, District Taniwel, West Seram Maluku. The aim was to determine the diversity of the orchid in the Lamasi Forest. Method used in this research is a qudrat linier transect method, plot size $10 \mathrm{~m}$ x $10 \mathrm{~m}$. The result showed that the orchid species were classified on 1 Classis, 2 Ordo, 1 Familia, 10 Genus and 13 Species. Value of diversity index showed that low diversity as well as value of dominant index.
\end{abstract}

Key words: orchid species, diversity, Lamasi Forest.

\section{Pendahuluan}

Indonesia dikenal sebagai negara yang kaya akan jenis flora dan faunanya. Anggrek merupakan familia terbesar yang menempati 7$10 \%$ tumbuhan berbunga dan memiliki kurang lebih 20.000 sampai 35.000 jenis. Anggrek liar Indonesia diperkirakan ada 4.000 - 5.000 jenis, $73 \%$ diantaranya adalah epifit dan hanya sekitar 19.000 spesies yang teridentifikasi (Dwi, 2007).

Anggrek adalah anggota familia Orchidaceae. Tanaman ini telah dikenal oleh masyarakat luas, memiliki nilai komersial dan estetika yang tinggi, sehingga banyak diminati baik sebagai tanaman hias maupun sebagai bunga potong. Dengan nilai jual tinggi,anggrek menjadi komoditas perdagangan baik dalam maupun luar negeri, sehingga berpotensi sebagai sumber devisa negara. Distribusi anggrek sangat luas dengan diversitas yang besar, umumnya di daerah tropis, pegunungan Himalaya, Asia Tenggara hingga Australia Utara. Keindahan dan keanekaragaman anggrek terutama terlihat pada morfologi dan warna bunga, meskipun bentuk vegetatifnya hampir sama, selain itu baunya yang khas, bentuk dan warna labelum yang unik juga akan menarik serangga polinator untuk membantu terjadinya proses penyerbukan.

Pulau Maluku menghasilkan jenis anggrek yang sangat menakjubkan. Salah satu yang paling menawan adalah anggrek bulan (Phalaenopsis amabilis). Terkait dengan sumber daya alam di Maluku yang berlimpah tumbuhan anggrek, yang paling banyak di Maluku Tengah, Seram Bagian Barat, Maluku Tenggara, Kepulauan Aru dan beberapa daerah lainnya. Selain Phalaenopsis ada juga Jenis-jenis anggrek lain yang terdapat di Maluku seperti, Vanda, 
Dendrobium, Spathoglotis, Acrorchis, Eria, Coelogyne, Aerides, Lapanemia, Phaius, Sarchantus,Trichogiottis, dan Pholidota (Lestari, 1985).

Di Desa Murnaten, tumbuhan anggrek dapat tumbuh liar di daerah pantai, pegunungan bahkan hutan belantara. Cara hidup tumbuhan anggrek ini adalah menempel pada benda lain seperti batang pohon, lempengan pakis, beberapa jenis ada yang tumbuh pada daerah bebatuan di lereng pegunungan, dan ada juga yang tumbuh memanjat pada batang tanaman lain tanpa merugikan tempat yang ditempeli. Berdasarkan latar belakang di atas peneliti tertarik untuk meneliti Keanekaragaman Jenis-Jenis Anggrek di Hutan Lamasi Desa Murnaten Kecamatan Taniwel Kabupaten Seram Bagian Barat Maluku.

Permasalahan yang dikemukakan dalam penelitian ini adalah Spesies-spesies anggrek apa saja dan bagaimana keanekaragaman jenis-jenis anggrek yang terdapat di Hutan Lamasi Desa Murnaten Kecamatan Taniwel Kabupaten Seram Bagian Barat Maluku. Berdasarkan permasalahan di atas, maka tujuan penelitian yang akan diperoleh, yaitu mengetahui spesies spesies anggrek dan mengetahui keanekaragaman jenis-jenis anggrek di hutan Lamasi Desa Murnaten Kecamatan Taniwel Kabupaten Seram Bagian Barat Maluku. Hasil penelitian ini diharapkan dapat memberikan informasi ilmiah bagi masyarakat Maluku mengenai jenis dan keanekaragaman jenis anggrek di Hutan Lamasi Desa Murnaten Kecamatan Taniwel Kabupaten Seram Bagian Barat Maluku.

\section{Metode Penelitian}

\section{Pengumpulan Data}

Pengambilan sampel dilakukan pada enam stasiun pengamatan dengan menggunakan metode transek liniar kuadrat (Fachrul, 2012). Luas hutan Lamasi adalah 2000 x 450 m, luas lokasi penelitian yaitu $4000 \mathrm{~m} 2$. Jarak stasiun I, stasiun II, stasiun III, stasiun IV, stasiun V, dan stasiun VI adalah $200 \mathrm{~m}$. Pada setiap stasiun pengamatan terbagi atas 4 garis transek, dengan jarak antara transek $50 \mathrm{~m}$. Pada setiap transek diletakan 10 petak pengamatan yang berukuran $10 \times 10 \mathrm{~m}$ dalam posisi berseling dengan jarak antara petak pengamatan adalah $20 \mathrm{~m}$. Selanjutnya pada setiap petak pengamatan dicatat spesies anggrek yang ditemukan.
Kemudian mengidentifikasi setiap tumbuhan anggrek, dan dihitung indeks keanekaragaman, dan indeks dominansi.

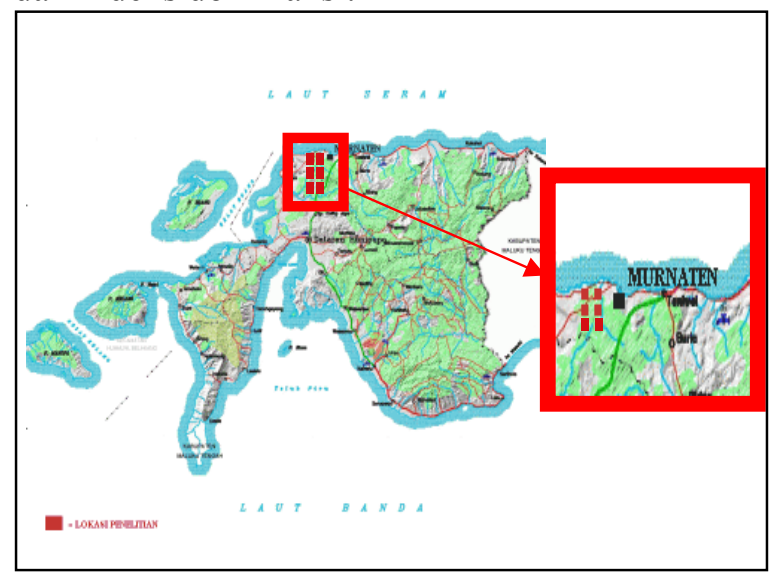

Gambar 1. Peta Seram Bagian Barat

(Sumber : Anonim 2013)

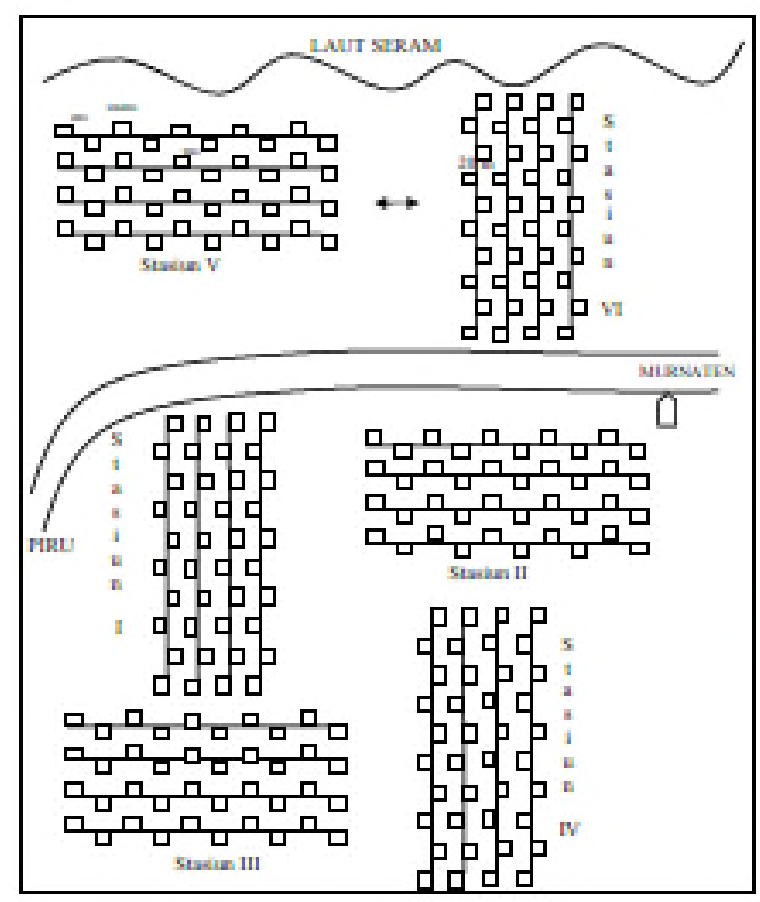

Gambar 2. Denah Transek Pengambilan Sampel

\section{Prosedur Kerja}

Survei dilakukan di hutan Lamasi Desa Murnaten Kecamatan Taniwel Kabupaten Seram Bagian Barat Maluku dengan jarak $9 \mathrm{~km}$ dari pemukiman penduduk. Koleksi dilakukan dengan menggunakan metode transek linier kuadrat dengan cara menjelajahi jalan setapak mulai dari bawah sampai ke atas bukit. Setiap jenis anggrek yang ditemukan dalam kegiatan survei diberi keterangan singkat mengenai habitat anggrek tersebut, kemudian dipotret untuk melengkapi data dokomentasi, kemudian 
diambil sampelnya dan dimasukan ke dalam plastik. Semua jenis anggrek yang terkoleksi diidentifikasi dengan mengacu pada (Pranata, 2005; Anonim, 1976; Anonim, 1979; Iswanto, 2001; Lestari, 1985; Gunawan, 1986; Azisz,(tt).

\section{Analisis Data}

Data untuk menghitung indeks keanekaragaman jenis adalah jumlah individu spesies ke-i dan jumlah total spesies. Indeks keanekaragaman jenis dapat dihitung menurut Shannon dan Wiener (1963) dengan rumus :

$$
\mathbf{H}^{\prime}=-\mathbf{\Sigma}(\mathbf{P i})(\ln \mathbf{P i})
$$

Dimana:

$\mathrm{H}^{\prime}=$ Indeks keanekaragaman jenis

$\mathrm{Pi}=$ Probabilitas penting untuk setiap spesies ke-

$\mathrm{i}=\mathrm{ni} / \mathrm{N}$

$\mathrm{ni}=$ jumlah individu spesies ke- $\mathrm{i}$

$\mathrm{N}=$ Jumlah total spesies

Data untuk menghitung indeks dominansi adalah jumlah individu spesies ke-i dan jumlah total spesies. Dominansi menunjukan spesies tertentu yang paling banyak terdapat dalam komunitas. Dominansi spesies di tentukan berdasarkan indeks Simpson sebagai berikut:

$$
\mathbf{D}=\mathbf{\Sigma}(\mathbf{P i})^{2}
$$

Dimana:

$\mathrm{D}=$ Nilai indeks dominansi spesies

$\mathrm{Pi}=$ Probabilitas penting untuk setiap spesies ke$\mathrm{i}=\mathrm{ni} / \mathrm{N}$
Jika $\mathrm{D}=1$ maka dominansi tinggi (ada spesies yang dominan),

Jika $\mathrm{D}=0$ maka dominansi rendah (tidak ada spesies yang dominan).

\section{Hasil dan Pembahasan}

\section{Jenis-jenis Anggrek di Hutan Lamasi Desa Murnaten}

Berdasarkan hasil penelitian 13 spesies terkoleksi yang terdiri dari 11 anggrek epifit dan 2 anggrek teresterial. Anggrek teresterial umumnya mempunyai daun yang lebar, helaiannya relatif tipis, tidak sekulen dan mempunyai banyak rambut akar. Anggrek epifit umumnya mempunyai daun tebal seperti kulit, dan mulut tersembunyi, akar tidak berambut kecuali pada bagian yang menempel pada tumbuhan lain (Suryowinoto, 1978).

Jenis-jenis anggrek yang di peroleh di lokasi penelitian merupakan anggota dari 1 kelas, 1 ordo, 1 famili, 10 genus, dan 13 spesies.

Data pada tabel 1 menunjukan bahwa sebagian besar spesies anggrek yang ditemukan di desa Murnaten adalah Phalaenopsis amabilis dengan jumlah individu sebanyak 69 individu, kemudian disusul oleh spesies Dendrobium dengan jumlah individu sebanyak 61 individu dan spesies Trichogiottis smitii.

Tabel 1. Struktur Taksa dan Jumlah Individu Anggrek, di Hutan Lamasi Desa Murnaten Kecamatan

\begin{tabular}{|c|c|c|c|}
\hline Famili & Genus & Spesies & $\begin{array}{l}\text { Jumlah } \\
\text { Individu }\end{array}$ \\
\hline \multirow{13}{*}{ Orcidaceae } & \multirow[b]{2}{*}{ Phalaenopsis } & Phalaenopsis amabilis & 69 \\
\hline & & Phalaenopsis amboenensis & 36 \\
\hline & Lapanemia & Lapanemia uliginosa & 27 \\
\hline & Acrorchis & Acrorchis rosella & 44 \\
\hline & Trichogiottis & Trichogiottis smitii & 53 \\
\hline & Sarchantus & Sarcantus subulatus & 31 \\
\hline & Spathogloottis & Spathoglotis plicata & 28 \\
\hline & \multirow{3}{*}{ Dendrobium } & Dendrobium stratiotes & 15 \\
\hline & & Dendrobium offine & 22 \\
\hline & & Dendrobium $\mathrm{sp}$ & 61 \\
\hline & Aerides & Aerides odorata & 32 \\
\hline & Eria & Eria brochianis & 24 \\
\hline & Vanda & Vanda celebica & 16 \\
\hline \multicolumn{3}{|c|}{ Jumlah } & 454 \\
\hline
\end{tabular}
Taniwel Kabupaten Seram Bagian Barat Maluku

dengan jumlah individu sebanyak 53 individu. Spesies yang paling sedikit ditemukan adalah
Dendrobium stratiotes dengan jumlah individu terendah yaitu sebanyak 15 individu. Banyaknya 
individu dari spesies Phalaenopsis amabilis, Dendrobium, dan Trichogiottis smitii, karena kehadiran ketiga spesies ini hampir ditemukan di setiap petak pengamatan, dengan kondisi pertumbuhan secara liar.

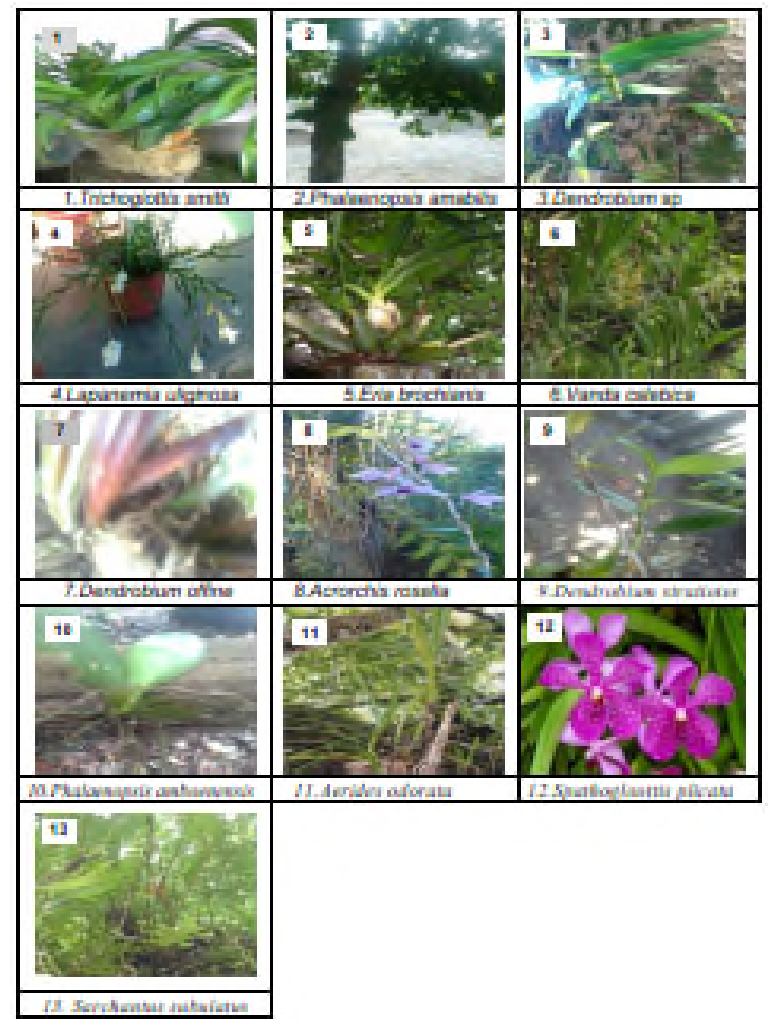

Gambar 3. Jenis-jenis Anggrek di hutan Lamasi Desa Murnaten

Dari hasil penelitian terlihat bahwa, jenis anggrek Phalaenopsis amabilis memiliki jumlah yang banyak bila dibandingkan anggrek lainnya. Jenis anggrek Phalaenopsis amabilis dapat tumbuh di dataran rendah hingga ke pegunungan dan umumnya hidup pada ketinggian 50-1.100 meter dari permukaan laut. Tanaman ini tumbuh epifit atau menempel di pohon-pohon yang cukup rindang dan menyukai tempat-tempat yang teduh serta lembap, terutama di hutan basah. Anggrek ini termasuk anggrek epifit monopodial yang rajin berbunga. Spesies anggrek ini merupakan tanaman asli Indonesia yang secara alamiah mampu beradaptasi atau menyesuaikan diri dengan kondisi lingkungan Indonesia (Lestari, 1985).

Berbagai jenis anggrek Dendrobium sangat diminati oleh masyarakat, karna menghasilkan bunga yang cantik dan warna yang menawan. Tanaman anggrek Dendrobium bersifat kospolitan (dapat di jumpai dari daerah tropis sampai ke daerah sub-tropis). Penyebaran anggrek ini mulai dari daerah pantai sampai ke pegunungan, cara hidupnya adalah menempel pada benda lain seperti batang pohon, lempengan pakis, beberapa jenis ada yang tumbuh di bebatuan di lereng pegunungan, dan ada juga yang tumbuh memanjat pada batang tanaman lain tanpa merugikan tempat yang ditempeli (bersifat epifit) (Solvia, 1988).

\section{Keanekaragaman dan Dominansi Jenis Anggrek di Hutan Lamasi Desa Murnaten}

Data perhitungan indeks keanekaragaman dan indeks dominansi dari jenis-jenis anggrek di Hutan Lamasi Desa Murnaten Kecamatan Taniwel Kabupaten Seram Bagian Barat Maluku dapat dilihat pada tabel 3 dan gambar 4.

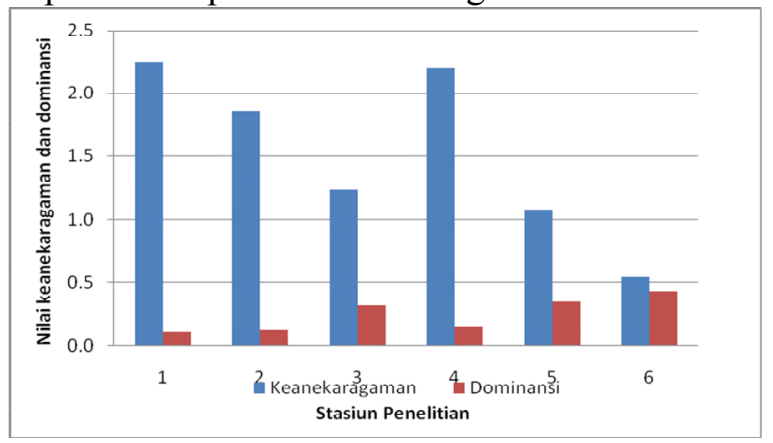

Gambar 4. Histogram nilai keanekaragaman dan dominansi jenis

Tabel 3. Nilai keanekaragaman, dominansi dan jumlah jenis anggrek di Hutan Lamasi Desa Murnaten Kecamatan Taniwel Kabupaten Seram Bagian Barat Maluku

\begin{tabular}{|l|l|l|l|l|l|r|}
\hline \multirow{2}{*}{\multicolumn{1}{|c|}{ Parameter }} & \multicolumn{7}{c|}{ Stasiun Penelitian } \\
\cline { 2 - 8 } & \multicolumn{1}{|c|}{ I } & \multicolumn{1}{c|}{ II } & III & IV & \multicolumn{1}{c|}{ V } & VI \\
\hline Keanekaragaman (H') & 2.254 & 1.856 & 1.24 & 2.201 & 1.081 & 0.541 \\
\hline Dominansi (D) & 0.109 & 0.12 & 0.318 & 0.148 & 0.344 & 0.429 \\
\hline Jumlah jenis & 10 & 10 & 4 & 10 & 3 & 3 \\
\hline
\end{tabular}


Berdasarkan tabel 3 dan gambar 4, diketahui bahwa nilai keanekaragaman jenis anggrek di stasiun I lebih tinggi yaitu sebesar 2,254, stasiun IV sebesar 2,201 stasiun II sebesar 1,856 , stasiun III sebesar 1,24, stasiun V sebesar 1,081 dan stasiun VI sebesar 0,541. Keanekaragaman jenis anggrek di semua stasiun bernilai kurang dari 2,3 yang mengindikasikan bahwa tingkat keanekaragaman jenis anggrek di semua stasiun adalah rendah.

Keanekaragaman jenis-jenis anggrek di Hutan Lamasi Desa Murnaten Kecamatan Taniwel Kabupaten Seram Bagian Barat Maluku berkategori rendah diduga karena adanya kelembapan udara terlalu tinggi yaitu $86,4 \%$ (statistik SBB) sehingga mempengaruhi pertumbuhan jenis anggrek teresterial. Pada kondisi kelembapan terlalu tinggi anggrek teresterial tidak menyukai banyak air sehingga mengakibatkan penyakit seperti penyakit pembusuk daun dan busuk tunas, anggrek teresterial ini menyukai naungan akan tumbuh pada lantai hutan dan sangat membutuhkan sedikit cahaya matahari untuk pertumbuhannya, akibat aktivitas masyarakat atas penebangan hutan liar sehingga merusak habitat jenis-jenis anggrek tersebut.

Nilai dominansi anggrek di stasiun I sebesar 0,109, stasiun II sebesar 0,12, stasiun III sebesar 0,318, stasiun IV sebesar 0,148, stasiun V sebesar 0,344, dan stasiun VI sebesar 0,429 (Tabel 3). Dari hasil penelitian menunjukan bahwa tidak terdapat dominansi spesies walaupun ditemukan spesies tertentu yang hadir dalam jumlah yang besar.

\section{Kesimpulan}

Berdasarkan hasil penelitian yang diperoleh dapat disimpulkan beberapa hal sebagai berikut Jenis-jenis anggrek yang terdapat di Hutan Lamasi Desa Murnaten Kecamatan Taniwel Kabupaten Seram Bagian Barat Maluku termasuk dalam 1 kelas, 1 ordo, 1 famili, 10 genus dan 13 spesies yaitu Phalaenopsis amabilis, Dendrobium sp, Trichogiottis smitii, Acrorchis rosella, Phalaenopsis Ambonesis, Sarchantus subulatu, Spathogloottis plicata, Lapanemia uliginasa, Dendrobium offine, Dendrobium startiotes, Vanda celebica, Achisdes odonata, dan Eria brochianis. Nilai indeks keanekaragam tertinggi berada pada stasiun I sebesar 2.254 menunjukan bahwa keanekaragaman jenis rendah. Nilai indeks dominansi tertinggi berada pada stasiun I sebesar 0.109 ini menunjukan tidak ada spesies yang mendominasi.

\section{Daftar Pustaka}

Anonim. 1976. Anggrek Indonesia. Lembaga Biologi Nasional-LIPI. Bogor

Anonim. 1979. Jenis-Jenis Anggrek. Lembaga Biologi Nasional-LIPI. Bogor.

Anonim. 2013. Peta Seram Bagian Barat. http://id.wikipedia.org/wiki/kabupaten Seram Bagian Barat. [diunduh Tgl. 5 Oktober 2013].

Aziz, D.(tt). Pembibitan dan Perwatan Anggrek. PT. Agromedia Pustaka. Jakarta.

Fachrul, M.F. 2012. Metode Sampling Bioekologi. Bumi Aksara. Jakarta

Gunawan, W. L. 1986. Budidaya Anggrek. PT. Agromedia Pustaka. Jakarta.

Lestari, S. S. 1985. Mengenal dan Bertanam Anggrek. Aneka Ilmu Semarang.

Pranata, S. A. 2005. Paduan Budidaya dan Perawatan Anggrek. PT. Agromedia. Jakarta.

Solvia, N. 1988. Mengenal dan Memelihara Anggrek. http://www.detiknews.com. [diunduh Tgl. 22 September 2013]. 